EESTI NSV TEADUSTE AKADEEMIA TOIMETISED. 28. KÓIDE KEEMIA, 1979, NR. 4

ИЗВЕСТИЯ АКАДЕМИИ НАУК ЭСТОНСКОП ССР. ТОМ 28 ХИмИЯ, 1979, N 4

Айли КОГЕРМАН, Э. ХЕИНСОО, Марет КРУЛЛЬ, О. КИРРЕТ, Эха УРБАС, Л. БЕРЕГОВАЯ, Л. ЕРШОВА

\title{
СОСТАВ ЛЕГКИХ ПРОДУКТОВ ПИРОЛИЗА ОГНЕЗАЩИЩЕННЫХ ПОЛИКАПРОАМИДНЫХ ВОЛОКОН
}

Aili KOGERMAN, E. HEINSOO, Maret KRULL, O. KIRRET, Eha URBAS, L. BEREGOVAJA, L. JERSOVA. SOTTIMISKINDLATE POLOKAPROAMIIDKIUDUDE KERGETE POROLOUSIPRODUKTIDE KOOSTIS

Aili KOGERMAN, E. HEINSOO, Maret KRULL, O. KIRRET, E. URBAS, L. BEREGOVAYA, L. YERSHOVA. THE COMPOSITION OF LIGHT PYROLYSIS PRODUCTS OF FLAMEPROOF POLYCAPROAMIDE FIBRES

Исследование процесса термодеструкции материалов методом пиролизной газовой хроматографии (ПГХ) позволяет оценить состав пиролизных газов почти в момент их образования, т. е. тогда, когда различные вторичные реакции между продуктами пиролиза еще не произошли.

Нами методом ПГХ был изучен состав первичных продуктов термодеструкции поликапроамидных (ПКА) нитей, наполненных фосфорсодержащими. огнезащитными добавками (антипиренами). Исследована зависимость выхода легких продуктов термодеструкции образцов ПКА $\left(\mathrm{H}_{2} \mathrm{O}, \mathrm{CO}, \mathrm{CO}_{2}, \mathrm{CH}_{4}\right.$, бензол, толуол, $\left.\mathrm{HCN}\right)$ от температуры пиролиза и типа антипирена.

Пиролизу подвергались образцы весом от 1 до 2 ме. Пиролиз (1225 c) проводился в аппаратуре, где реактор-пиролизатор и хроматограф были соединены в одну систему в проточном режиме работы в токе инертного газа (гелия). Расчет площадей пиков на хроматограммах проводился при помощи цифрового автоматического интегратора И-02. Условия хроматографирования приведены ранее [1-3].

Исследовались образцы ПКА со следующими добавками *: обр. 1 контрольный; обр. 2: фосфоран $1-10 \%$; обр. 3: фосфоран $2-10 \%$; обр. 4 : фосфоран 3-5\%; обр. 5: фосфоран $3-5 \%$, соединение стибия - $5 \%$; обр. 6: фосфоран 3-5\%, соединение висмута - 5\% .

Ингибирующее действие фосфорсодержащих антипиренов на горение целлюлозных, материалов связано, в частности, с дегидратацией полимера. Механизм действия этих антипиренов на ПКА не известен [ $\left.{ }^{4}\right]$.

В первую очередь представляет интерес количественное определение $\mathrm{H}_{2} \mathrm{O}$ в продуктах пиролиза наполненных поликапроамидных нитей в зависимости от типа антипирена. На рис. 1 приведены данные таких опытов. Выделение пиролизной воды начинается приблизительно при $200^{\circ} \mathrm{C}$. Все изученные антипирены повышают выход пиролизной воды по сравнению с контрольным полимером. Это может быть связано, с одной стороны, с разложением самих антипиренов, а, с другой, - с дегидратацией молекул ПКА.

* Все образцы ПКА содержат 2-3\% пластификатора. 


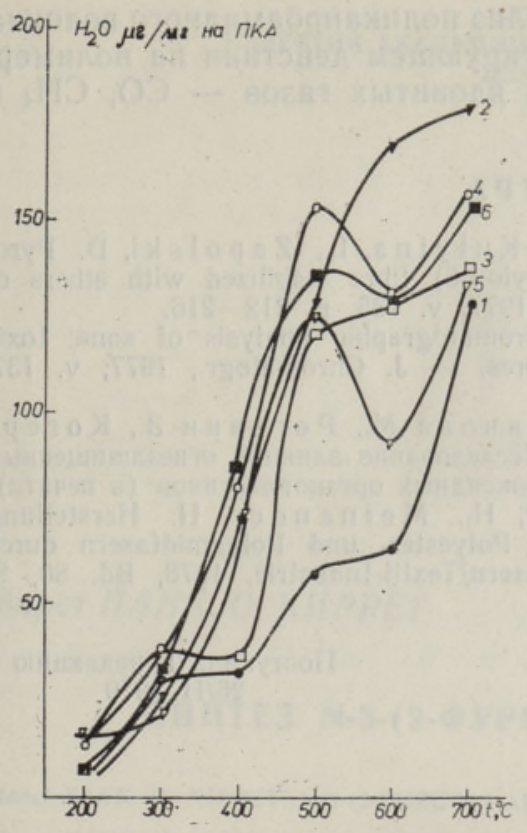

Рис. 1. Выход $\mathrm{H}_{2} \mathrm{O}$ при пиролизе наполненных фосфорорганическими антипиренами ПКА-волокон в зависимости от температуры и типа антипирена.

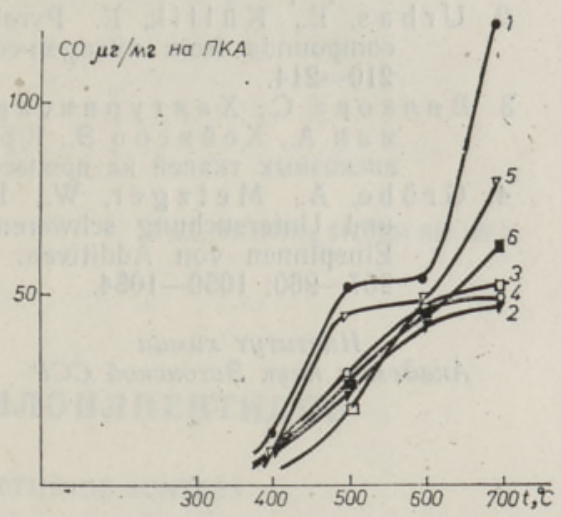

Рис, 2. Выход СО при пиролизе наполненных фосфорорганическими антипиренами ПКА-волокон в зависнмости от температуры и типа антипирена.

Кривые температурной зависимости выхода воды при пиролизе образцов наполненного фосфорсодержащими антипиренами полимера имеют максимум при $\approx 500^{\circ}$, т. е. при температуре самовоспламенения поликапроамидного волокна.

Из легких продуктов термодеструкции определялось количество СО, $\mathrm{CH}_{4}, \mathrm{CO}_{2} . \mathrm{Ha}$ рис. 2 приведена температурная завиоимость выхода $\mathrm{CO}$ от состава волокна. Выделение СО начинается в области температур $300-400^{\circ}$; все фосфорсодержащие антипирены снижают выход СО при пиролизе по сравнению с контрольными образцами ПКА.

Выделение $\mathrm{CO}_{2}$ при пиролизе начинается приблизительно при $300^{\circ}$; количество $\mathrm{CO}_{2}$ колеблется в пределах от 1 до $3 \mu 2 /$ м ПКА и мало зависит от температуры и структуры антипирена. Все фосфорсодержащие антипирены несколько снижают выход $\mathrm{CO}_{2}$ при пиролизе ПКА.

$\mathrm{CH}_{4}$, бензол и толуол появляются в продуктах пиролиза наполненного ПКА при температуре $\approx 400^{\circ}$; в области температуры самовоспламенения поликапроамидного волокна $\left(500^{\circ}\right)$ их содержание незначительно. Выход $\mathrm{CH}_{4}$ (от 0,5 до $3,5 \mu 2 /$ мг ПКА), бензола (от 0,5 до $3,0 \mu 2 /$ м ПКА) и толуола (от 0,5 до $1,0 \mu 2 /$ м ПКА) в малой степени зависит от присутствия в полимере антипирена и его структуры.

В продуктах термодеструкции азотсодержащих органических материалов всегда имеется HCN. В продуктах термодеструкции наполненного ПКА НCN появляется в области температур $450-500^{\circ}$. С повышением температуры пиролиза до $900^{\circ}$ выход $\mathrm{HCN}$ увеличивается от 1 до $120 \mu 2 /$ М ПКА, фосфорсодержащие антипирены несколько снижают вы-. ход $\mathrm{HCN}$ при пиролизе.

На основе приведенных данных можно сделать вывод, что влияние 
фосфорсодержащих антипиренов на пиролиз поликапроамидного волокна заключается, в частности, в их дегидратирующем действии на полимер, а также в снижении выхода горючих и ядовитых газов $-\mathrm{CO}, \mathrm{CH}_{4}$ и $\mathrm{HCN}$.

\section{ЛИТЕРАТ У РА}

1. Krull, M., Kogerman, A., Kirret, O., Kutyina, L., Z a polski, D. Pyrolysis gas chromatography of capron (nylon-6) fibre stabilized with ethers of 4-oxydiphenylamine. - J. Chromatogr., 1977, v. 135, p. 212-216.

2. Urbas, E., Küllik, E. Pyrolysis gas chromatographic analysis of some toxic compounds from nitrogen-containing fibres. - J. Chromatogr., 1977, v. 137, $210-214$.

3. Вилкова С., Халтуринский Н., Тюганова М., Роговин 3., Когер м а н А., Хей нсоо Э., К р улль $М$. Исследование влияния огнезащищенных вискозных тканей на процесс горения эпоксидных органопластиков (в печати).

4. Gröbe, A., Metzger, W., Herlinger, H., Me in ander, H. Herstellung und Untersuchung schwerentflammbarer Polyester- und Polyamidfasern durch Einspinnen von Additiven. - Chemiefasern/Textil-Industrie, 1978, Bd. 80, S. 957-960; 1050-1054.

Ннститут химии

Академии наук Эстонской ССР
Поступила в редакцию 26/II 1979 